\title{
La e-migración: un nuevo espacio para pensar la retórica de la integración en las políticas migratorias
}

\section{E-migration: a new space to think the rhetoric of integration in migration policies}

\author{
Nihil Olivera Cajiga \\ Doctor, Universitat Autònoma de Barcelona
}

Fecha de recepción: 21 de septiembre de 2012

Fecha de revisión: 18 de noviembre de 2012

Para citar este artículo: Olivera Cajiga, N. (2013): La e-migración: un nuevo espacio para pensar la retórica de la integración en las políticas migratorias, Icono 14, volumen 11 (1), pp. 233-261. doi: 10.7195/ri14.v11i1.509 


\section{Resumen}

Este artículo, basado en un estudio comparativo de migrantes franceses y ecuatorianos en Barcelona, discute la retórica de la integración en las políticas migratorias dentro del contexto de las tecnologías de la información y la comunicación (TIC). Los resultados que se presentan permiten problematizar las relaciones de los migrantes en Barcelona a partir de sus prácticas sociales en las TICs, así como también plantear la existencia de unas características tecnológicas, geográficas y sociales (TGS) que crean un nuevo espacio que llamamos e-migración. Se argumenta en este artículo que el discurso de la integración y las TICs, que forma parte de la retórica de las administraciones de gobierno catalana, ocultan desigualdades estructurales entre los migrantes comunitarios y no comunitarios. El estudio de caso de franceses y ecuatorianos migrantes en Cataluña es una muestra de cómo se gestiona la diversidad en clave cultura para categorizar a determinadas poblaciones y no para integrarlas.

\section{Palabras clave}

Integración - política - e-migración - ecuatorianos - franceses - TIC - Barcelona retórica

\section{Abstract}

This article, based on a comparative study of French and Ecuadorian migrants in Barcelona, discusses the rhetoric of integration in migration policies within the context of information and communication technologies (ICT). The results presented allow to question the relationship of migrants in Barcelona taking into account their ICT social practices, as well as propose the existence of technological, geographical and social (TGS) characteristics to create a new space we call e-migration. It is argued in this article that the discourse of integration and ICT, which is part of the rhetoric of the Catalan government administrations, hides structural inequalities between migrants from EU and outside of the EU. The case study of French and Ecuadorian migrants in Catalonia shows how cultural diversity is used to classify certain populations and not to integrate them. 


\section{Key Words}

Pintegration - policy - e-migration - Ecuadorians - French - ICT - Barcelona - rhetoric

\section{Introducción}

Este artículo es parte de una investigación amplia ${ }^{1}$ sobre el modo en que las TICs estarían participando en el proceso de "integración social" de la población migrada en Cataluña a partir del concepto propuesto de e-migrantes, y distinguiendo entre migrantes comunitarios y no comunitarios ${ }^{2}$. El propósito de este artículo apunta a deconstruir, siguiendo la visión critica de la Sociedad de la información (Almiron, 2002; Becerra, 2003; Jiménez Becerra, 2010; Mattelart, 2007; Tremblay, 2003; Vercelli, 2010; Webster, 2006), el discurso retórico de la integración de las políticas públicas migratorias y proponer una nueva perspectiva analítica teniendo en cuenta los nuevos espacios tecnológicos, geográficos y sociales (TGS) que conforman lo que llamamos la e-migración.

Se analiza si la inmigración no comunitaria -que suele ser enunciada retóricamente desde la administración de gobierno como un "problema cultural" y objeto de intervenciones sociales específicas- tiene, con el uso y apropiación de las TICs, las mismas posibilidades de progreso que los inmigrantes comunitarios en Cataluña. Focalizar la atención en estos colectivos y en las políticas de integración establecidas por el Pacto Nacional de la Inmigración (PNI) en Cataluña nos permite discutir en qué condiciones se gestionan las diferencias, las desigualdades, la inclusión-exclusión y los dispositivos de explotación en los procesos interculturales. Tal comparación se ubica en un contexto donde el capital social se habría extendido a las relaciones internacionales, desplazando su eje de los territorios a los recursos intangibles de la movilidad y las conexiones.

En el apartado "metodología" que sigue a continuación, se explica la implementación de las 150 encuestas a franceses y ecuatorianos e-migrantes con el fin de analizar sus usos, sus prácticas sociales y su apropiación de las TIC; así como también las entrevistas en profundidad a los gestores de las políticas migratorias catalanas. Los resultados del análisis se presentan a continuación junto con una exploración de: a) la relación entre los criterios retóricos de integración establecidos 
por las políticas públicas de la Unión Europea (UE) y Cataluña en el contexto de la Sociedad de la información; b) el uso y apropiación de las TICs en los e-migrantes; y c) el desarrolla del concepto de nuevos espacios tecnológicos, sociales y geográficas (TGS) que configuran lo que denominamos e-migración. Nuestro análisis examina la hipótesis de que las políticas de la integración y las TICs, que forman parte de la retórica de las administraciones del gobierno catalán, se orientan a categorizar y clasificar a determinadas poblaciones no comunitarias para controlarlas y no para integrarlas. Por último, en el apartado de discusión, el artículo también busca contribuir al desarrollo de un marco teórico, la e-migración, como un punto de partida y un intento de repensar una nueva retórica de la e-migración internacional.

\section{Metodología}

El estudio de caso que se presenta consiste en una investigación empírica realizada en Cataluña entre 2010 y 2011 con migrantes comunitarios (franceses) y no comunitarios (ecuatorianos). Estos grupos fueron elegidos por su representación numérica en España en general, y en Cataluña en particular ${ }^{3}$. Se parte de que la muestra es representativa de la población (aunque sea una representatividad sociológica, no estadística). Nuestra muestra no buscó equiparar a ecuatorianos ricos o franceses ricos y/o ecuatorianos pobres y franceses pobres, debido a que tal selección hubiera sido forzada y no representativa de la población real de ambos colectivos que residen actualmente en Cataluña. La muestra está formada entonces por el conjunto de la población mayor de 15 años, de ambos sexos, de diferentes estratos socioeconómicos que viven dentro del Área Metropolitana de Barcelona.

La selección de la inmigración procedente de Ecuador y Francia, como casos para un análisis comparado sobre estas imbricaciones, se explica por las siguientes características específicas:

a) la pertenencia al marco legal europeo (comunitarios) y la no pertenencia a los derechos que otorga la ciudadanía europea (no comunitarios); b) los momentos de llegada de los colectivos, el tiempo de residencia en Cataluña y el trato que recibe uno y otro colectivo migrante según sea el país de origen; c) status social y económico (rentas); d) los proyectos migratorios: una migración estable entre las familias francesas y el retardo de la reagrupación familiar y estabilidad familiar

ICONO14 | Año 2013 Volumen 11 № 01 | ISSN: 1697-8293 | DOI: ri14.v11i1.509 
para el caso de los ecuatorianos; e) inserciones laborales en Cataluña; f) las inserciones escolares (escuela pública, privada, concertada o francesa) de los hijos de ambos colectivos; g) el consumo de periódicos, televisión y noticias en Internet (país de origen o de destino).

Además, para situar los resultados de la investigación en la especificidad de la sociedad catalana, se necesitaba que la muestra de la población e-migrada de franceses y ecuatorianos a Cataluña fueran usuarios de las TICs. Así, la muestra no incluye a los no usuarios de las TICs, ya que la atención se centró en las prácticas y relaciones sociales transnacionales de quienes están directamente insertos en las formas de comunicación electrónica.

Indudablemente ambos colectivos seleccionados para este estudio, franceses (comunitarios) y ecuatorianos (no comunitarios), están condicionados por las políticas migratorias de formas diferentes. Pero también ambas colectividades están atravesadas y mediadas por la las TICs y por el discurso político de la Comisión Europea, que promete un espacio social más igualitario, participativo y cohesionado con el acceso de los migrantes a la tecnología (Europa, 2010).

Nuestro interés fue explorar si el acceso a las TICs de ambos colectivos (franceses y ecuatorianos) los aproximan o alejan de los criterios de integración, de igualdad y cohesión social que instituye el Pacto Nacional para la Inmigración (PNI) aprobado en 2008 en Cataluña. Para ello, el diseño de nuestra investigación comprendió dos etapas. La primera -cuantitativa- consistió en una encuesta estructurada a los migrantes franceses y ecuatorianos para: a) obtener datos tanto del uso que los e-migrantes realizan de las TICs, como de su "grado de integración"; y b) para establecer tipologías según las variables relacionadas con los objetivos de investigación. Los ítems de la encuesta destinados a medir el grado de integración se han establecido utilizando como base el reto 1 (fomentar la participación en la vida pública) y el reto 2 (hacer del catalán la lengua pública común) que establece el PNI, correspondientes al Eje 3: "integrar en una cultura pública común" (2008, PNI). Se analizaron esos dos retos de entre los cinco establecidos por el PNI porque, según los criterios establecidos en nuestra investigación, eran los que permitían establecer una serie de indicadores cuantificables que ayudaban a apuntar luego una serie de correlaciones para analizar y explicar si se corresponde el imaginario social que construye a los franceses como más integrados que los ecuatorianos. Los ítems destinados a medir el uso real de las TICs se diseñaron tomando como modelo

DOI: ri14.v11i1.509 | ISSN: 1697-8293 | Año 2013 Volumen 11 N 01 | ICONO14 
general el formulario de la investigación sobre la "Sociedad Red" en Cataluña, impulsado por l'Institut de Recerca de la Universitat Oberta de Catalunya (IN3, 2007).

La segunda etapa -cualitativa- incluyó grupos focales de migrantes y entrevistas en profundidad a los secretarios de inmigración del gobierno catalán, Adela Ros y Oriol Amorós, de Esquerra Republicana (ERC), quienes gestionaron la migración en esa comunidad autonómica durante los últimos ocho años, y con el fin de captar las subjetividades del concepto de integración dentro de los nuevos espacios TGS y de entender los mecanismos y las relaciones sociales que subyacen a la medición específica. Esta metodología permitió comparar y relacionar la retórica política de la "integración" del PNI con las prácticas y las lógicas de producción y recepción social que las comunidades ecuatorianas y francesas establecieron mediante el uso de las TICs en Cataluña (Olivera, 2011).

\section{La retórica del lenguaje político migratorio}

El lenguaje, intuyó el filósofo Wilhem Von Humboldt en 1805, se concibe como un instrumento que permite expresar el pensamiento. Pero fue Friedrich Nietzsche quien más tarde postuló que el lenguaje posee una naturaleza esencialmente retórica. Para él, las palabras no coinciden con las "cosas" que pretenden designar; las palabras hacen alusiones figuradas (tropos), saltos de sentido, que traducen las experiencias sensibles de los sujetos (Valverde, 1993). Nietzsche, de esta manera, nos muestra que la verdad se construye no negando su existencia, sino afirmando que su conocimiento es siempre imperfecto y tentativo.

"(La verdad) se lleva a cabo partiendo de sensaciones que "hacen sentido" sólo en la medida en que son transubstanciadas lingüísticamente. De manera que nuestro conocimiento de esas realidades externas y de nuestras realidades internas es siempre un tropismo, un salto de sentido, una genuina e inevitable traducción" (Chillón, 1998, p. 10)

En otras palabras, la realidad objetiva no existe, solo accedemos al lenguaje que se construye a partir de tropos, de lo verosímil, parafraseando la retórica aristotélica. La verdad es la creencia que se sostiene en la esfera de la opinión común (dóxa) y no de la episteme o conocimiento filosófico y científico (Chillón, 1998). En la comunicación, entendida de esta manera, no hay ninguna naturalidad no-retórica en

ICONO14 | Año 2013 Volumen 11 № 01 | ISSN: 1697-8293 | DOI: ri14.v11i1.509 
el lenguaje, ya que el propio lenguaje es el resultado de artes puramente retóricas que no enseñan, sino transmiten una percepción subjetiva a otros.

El discurso que la retórica política instituye, como cualquier forma de comunicación, no está exenta del acto de poner en común las experiencias particulares mediante enunciados, con el fin de establecer acuerdos intersubjetivos sobre el "mundo de todos" para conformar un mapa, que por convención cultural, llamamos "realidad". Es a través de la cultura y la construcción de enunciados lingüísticos que se va delimitando "una" realidad común que utilizarán los individuos de forma consciente o no.

Las políticas públicas no dejan de ser discursos que constituyen y construyen una realidad entre muchas, que involucra la actividad de nombrar y clasificar, además de vincular contextos sociales y culturales, y excluyen formas de pensar alternativas. Como explica Ibáñez (2002), a través de las políticas se determinan agendas, se construyen y definen problemáticas, se elaboran e imponen explicaciones y se ofrecen soluciones. La retórica sobre la inmigración -político, jurídico, social, mediático, etc.- instaura formas de clasificar a las personas y de definir problemas que repercuten en importantes consecuencias materiales y simbólicas, instala determinadas visiones y di-visiones del mundo. Así, la comunicación política configura ideas y modos de pensar a partir de una ideología dominante, fijando los términos de referencia y marginalizando alternativas. Las políticas públicas de inmigración, a partir de las leyes y los planes de migración, se constituyen, bajo esta concepción, en discursos hegemónicos que otorgan autoridad institucional a una forma de pensar en detrimento de otras (Shore y Wright, 1997).

La ideología hegemónica que se inspira o se apoya en la vinculación de lo anormal con lo normal, de la periferia y su centro, de los "otros" y "nosotros", lo comunitario y no comunitario, es contenedora de las claves que pueden aclarar el origen y el desarrollo de la legitimidad indispensable en todo sistema moderno de dominación y explotación.

“Estudiar la retórica de esos discursos permite comprender el proceso complejo de transposición de los elementos sociales, contradictorios y conflictivos, profundo e irreductiblemente antagónicos, y su sustitución por un aparato dialéctico que expresa contradicciones sobre un eje mediador cuyos polos son lo normal y lo anormal" (Bartra, 1996, p. 39).

DOI: ri14.v11i1.509 | ISSN: 1697-8293 | Año 2013 Volumen 11 N 01 | ICONO14 
Así, los segmentos sociales afectados en contradicción antagónica por tal modelo dicotómico (normal-anormal) se encuentran sustituidos por cadenas de signos, ceremonias, ritos, mensajes y símbolos, percibidos y estudiados en campos de la vida donde aparecen saltos de sentido difícilmente descifrables (Bartra, 1996).

Las políticas desplegadas bajo la "integración" construyen a partir de su retórica comunicativa una realidad, un imaginario social, que señala a los migrantes comunitarios como más integrados que los no comunitarios en las sociedades de destino europeas. El secretario de Inmigración de la Generalitat de Cataluña, Oriol Amorós, y su retórica política migratoria son un ejemplo de la construcción de esos imaginarios sociales. Para él, el migrante no comunitario castellanoparlante "pone en riesgo la lengua catalana, porque hablan castellano". Amorós, sostiene y reproduce el imaginario de la migración en general, y la no comunitaria castellana, como una amenaza del equilibrio demográfico de la lengua catalana.

“Hay una perspectiva de la catalanidad respecto de los latinoamericanos. Se les ve como personas que hablan en castellano y que alteran el delicado equilibrio demográfico entre las lenguas en nuestro país. Hay un hecho objetivo y es que la migración latinoamericana aumentó mucho el número de parlantes castellanos en nuestro país. La inmigración en general disminuye el porcentaje de catalanoparlantes en nuestro país $\mathrm{y}$, por tanto, la viabilidad de nuestra lengua que depende de si tiene prestigio y de si es utilizada por una mayoría de catalanes. ¿Es una amenaza irreversible? No, porque también es verdad que la inmigración aumentó el numero de hablantes catalanes y es una lengua que la están aprendiendo miles de personas. Este año (2010) hay 126 mil estudiantes que son extranjeros, 126 mil nuevos hablantes. Es un esfuerzo muy grande en términos absolutos y pequeños en términos relativos" (Oriol Amorós, secretario de Inmigración de la Generalitat de Cataluña)

El secretario de Inmigración reafirma así el imaginario social lingüístico del migrante no comunitario castellano parlante para después enunciarlo como un potenciador de la lengua catalana futura. En la entrevista se le señala que son los hijos de los latinoamericanos quienes se están formando en las escuelas catalanas y que la llamada "segunda generación de inmigrantes" ya sabrá escribir, leer y hablar en catalán, un hecho que no ocurrirá con los hijos de los franceses, que envían a sus hijos a formarse a las escuelas y liceos francesas. Cuando se invierte el imaginario, el secretario de Inmigración necesita consultar datos y su respuesta

ICONO14 | Año 2013 Volumen 11 № 01 | ISSN: 1697-8293 | DOI: ri14.v11i1.509 
no desprende tanta seguridad.

“No... ¿Cuántos franceses van al liceo francés? (Se levanta y va a buscar estadísticas y datos propios de la secretaría). Es verdad que tenemos pocos franceses en la escuela, pero no creo que haya tantos en el liceo francés, hay uno solo que yo sepa. El mayor porcentaje de franceses está en Barcelona, hay 35 mil franceses y 13 mil están en Barcelona, en Sant Cugat 1.000, y en Castelldefels 1000 también. Y en L’Hospitalet sólo 357. Pero en el liceo francés se enseña catalán también, ¿no? No se si lo aprenden, pero se lo enseñan" (Oriol Amorós, secretario de Inmigración de la Generalitat de Cataluña).

El lenguaje retórico político, como el que instituye Amorós, es sin duda una de las claves en la percepción subjetiva de la inmigración no comunitaria para el resto de la sociedad. Este lenguaje luego repercute en importantes consecuencias materiales y simbólicas, concretas, como la del PNI, que instala determinadas visiones y di-visiones de la migración. Además, da forma a las estructuras de entendimiento de los sujetos y de las subjetividades, estableciendo una artificialidad y una interdependencia del "problema" de la migración y la "integración". Según Stolcke:

"el 'problema de la inmigración' ha sido construido, en todo caso, como una amenaza política a la identidad nacional, a causa de la diversidad cultural de los inmigrantes, porque el Estado-nación se concibe como basado en una comunidad delimitada y específica que moviliza un sentimiento de pertenencia y lealtad compartido basado en una lengua, tradición cultural y creencias comunes" (1994, p. 248).

A partir de la utilización del lenguaje institucional, en tanto que instrumento de nominación, las políticas migratorias adquieren un papel fundamental, y no por lo que dicen sino por lo que hacen, por lo que instituyen, por el tipo de relaciones que habilitan y las que inhiben. Además, estas políticas tienen un papel relevante en la construcción de los imaginarios sociales, ya que producen textos legislativos que enuncian al "otro" en la construcción que esa sociedad hace de su imaginario. Los imaginarios sociales son los anclajes en la memoria, en sus ritos y en sus formas, en sus escenarios de interacción y de repetición, en sus mitos, en sus estereotipos, etc., que una sociedad tiene de sí misma o de otras. Es a partir del imaginario social que una sociedad designa su identidad: "elabora una representación de sí misma, marca la distribución de los papeles y los roles sociales, expresa e impone ciertas creencias, etc. Esa identidad colectiva marca un territorio y define

DOI: ri14.v1 1i1.509 | ISSN: 1697-8293 | Año 2013 Volumen 11 Nº1 | ICONO14 
las relaciones con los otros" (Ford, 1999, p. 64).

\section{La cultura identitaria como retórica política de}

\section{la exclusión en España y Cataluña}

La identidad cultural funciona y funcionó como uno de los discursos retóricos migratorios más recurrentes de la política de la exclusión. A continuación se muestran algunos ejemplos. La profecía de Huntington sobre el choque de civilizaciones, la idea de distancias culturales y de integración en base a "las raíces culturales" son argumentos atractivos para los políticos, y son citadas en algunos debates políticos y mediáticos como parte de una retórica culturalista de la exclusión. En febrero de 2000, el ex delegado del gobierno español para la Inmigración, Enrique Fernández-Miranda, señalaba que "la lengua, la cultura común y la práctica de la religión católica son elementos que facilitan la integración de los extranjeros en España". Una posición similar fue sostenida por el ex Defensor del Pueblo, Enrique Múgica, quien propuso que el Estado favoreciera la inmigración latinoamericana ${ }^{4}$.

En Cataluña, Marta Ferrusola, esposa del entonces presidente de la Generalitat, Jordi Pujol, criticó en febrero de 2001 a los inmigrantes que vivían en Cataluña y los acusó de intentar "imponer constantemente" sus costumbres y su religión, tal como recoge el diario El periódico. Ferrusola, también apuntó que, en referencia a las partidas destinadas por la Generalitat a los extranjeros, "las ayudas son para una gente que no sabe ni lo que es Cataluña". También insistió en que es preciso integrar a los inmigrantes "de arriba a abajo". Además marcó una línea identitaria a partir de la lengua catalana y señaló que: “Estos inmigrantes han ido a parar a un país, y saben decir 'Buenos días, buenas tardes, dame de comer', y poco más. Después, hablan medio en su lengua, medio en castellano. Siento decirlo, pero es así". Ferrusola propuso que el aprendizaje del catalán sea el primer paso para integrar a los recién llegados: “El que se quede en Cataluña que hable catalán, porque el castellano sí que lo hablan".

El ex secretario general de Esquerra Republicana de Cataluña y ex presidente del Parlament, Heribert Barrera, sostenía, tal como se recoge en el diario La Vanguardia en febrero de 2001, que "cuando el señor Jörg Haider (ex líder de la 
ultraderecha austríaca) dice que en Austria hay demasiados extranjeros no está haciendo ninguna proclama racista". Barrera señalaba también que "si continúan las corrientes inmigratorias actuales Cataluña desaparecerá"; y hacía referencia al artículo 13.1 de la Constitución, que señala que los extranjeros gozarán en España de las libertades públicas, pero "en los términos que establezcan los tratados y la ley". Por ello, dijo que, "de haber sido diputado, habría votado a favor de la Ley de Extranjería del PP". Barrera y Ferrusola declaraban en su momento el peligro inminente de la cultura catalana si los inmigrantes entraban de forma masiva. Pensaban que la cultura catalana se podía perder. Los inmigrantes a los que hacían referencia eran los extracomunitarios y no los comunitarios.

En mayo de 2002, el ex presidente de la Generalitat de Catalunya, Jordi Pujol, definía el origen musulmán de la mayoría de los inmigrantes de la región catalana como una dificultad para la integración. Ese mismo año, los vecinos de Premià del Mar, en la provincia de Barcelona, se manifestaron en reiteradas oportunidades en contra de la construcción de oratorios musulmanes en el perímetro de la ciudad, en un terreno comprado por un grupo de inmigrantes para ese fin. En relación a las manifestaciones, el 21 de mayo de 2002 el diario El País publicaba las declaraciones de Pujol: "Cataluña ha sido y sigue siendo una tierra de acogida", donde señalaba que, al "mismo tiempo que integra a los inmigrantes, quiere conservar su propia identidad y cultura". Pujol categorizaba y clasificaba la inmigración que recibía Madrid proveniente de Sudamérica como más fácil de integrar: "Un ecuatoriano trasplantado en Madrid se encuentra como en casa (...) ni se nota".

Los discursos políticos y las praxis de las políticas públicas en inmigración parecían entonces recorrer un mismo camino, el de la identidad cultural, instaurando formas de clasificar y categorizar a las personas y definiendo una "realidad", un "problema". Estos discursos construyeron luego importantes realidades materiales, tal como se comprueba a continuación. En los procesos de regularización de los años 2000 y 2001 las cifras de los dos grupos de indocumentados más numerosos eran: los marroquíes con un $69 \%$ y los ecuatorianos con un $87 \%$. En el proceso de regularización de 2000 , el $23 \%$ de las solicitudes presentadas eran de algún ciudadano latinoamericano. El 85\% obtuvo una respuesta afirmativa. En 2001 los latinoamericanos presentaron un tercio de las solicitudes y obtuvieron una tasa de reconocimiento del 84\%. En el proceso de regularización por arraigo de 2001, por primera vez los marroquíes no fueron los más numerosos, sino los ecuatorianos $\mathrm{y}$,

DOI: ri14.v11i1.509 | ISSN: 1697-8293 | Año 2013 Volumen 11 N 01 | ICONO14 
en segundo lugar, los colombianos. Estas dos nacionalidades reunieron el 52\% de las solicitudes aprobadas. En esa oportunidad la tasa de reconocimiento para las solicitudes de ecuatorianos fue del $81 \%$ y para los marroquíes del 48\% (Izquierdo, 2002).

\section{La retórica del lenguaje de la Sociedad de la}

\section{información}

La retórica actual de las política migratorias como las del PNI, a partir del discurso de las TICs, construyen una nueva realidad que promete alcanzar a todos los individuos promoviendo la inclusión y la mejora de la participación social y la cohesión. El discurso de las TICs y lo transnacional, que acompaña la definición de la Sociedad de la información, ocupa una posición decisiva dentro del imaginario global que la defiende como el paradigma dominante del cambio y como garantía de un mundo más solidario, transparente, libre e igualitario. Una retórica que “genera efectos de realidad, movilizan a los responsables de las decisiones políticas y económicas y orientan la acción y la investigación en un determinado sentido y no en otro" (Mattelart, 2007, p. 11). Para Mattelart, bajo el mito de la tecnología se trasluce la materialidad de un esquema operativo de remodelaciones del orden cultural, económico, político y militar del planeta. La Sociedad de la información sería entonces, según el discurso utópico que Mattelart critica, un lugar-espaciotiempo en el cual los migrantes encontrarían mayor solidaridad, libertad e igualdad.

Un ejemplo del discurso de igualdad en las políticas migratorias de inclusión en la Sociedad de la información lo encontramos en el informe estratégico de la Comisión Europa i2010. El informe señala a las TICs y a la inclusión social como una referencia para las orientaciones políticas generales de la Sociedad de la información y de los medios de comunicación, y se propone como un marco europeo para reforzar la cohesión social, económica y territorial. Para lograr el objetivo de una Sociedad de la información que sea incluyente, que ofrezca servicios públicos de gran calidad y que promueva la calidad de vida, la Comisión planteaba una iniciativa europea sobre inclusión electrónica (e-inclusión) que abordara la igualdad 
de oportunidades, las competencias en TICs y las fracturas regionales.

Las políticas públicas migratorias de la UE y las TICs confluyen, como se observa en el documento i2010, en un proyecto de inclusión digital dentro de la Sociedad de la información. Dentro de las actividades previstas por las directivas de la UE para conseguir que "nadie se quede atrás" y pueda acceder a los beneficios de las TICs, se pretende que la inclusión digital reduzca las diferencias en el uso de las TICs y se promuevan para superar la exclusión, mejorar el rendimiento económico, tener oportunidades de empleo, mejorar la calidad de vida y mejorar la participación social y la cohesión (Europa, 2010).

Otro ejemplo lo encontramos en el informe estratégico de la Comisión Europa 2020. Entre sus objetivos, se encuentra la integración de la inmigración en la población activa. Tal objetivo se basa en los criterios de “lucha contra la pobreza, la exclusión social, la modernización de los mercados laborales y los sistemas de formación que permitan construir una sociedad cohesionada" (Europa 2020, 2010, p. 25). Sin embargo, según se desprende del documento, esta iniciativa está todavía en un proceso embrionario, ya que aún no existen planes ni programas europeos en funcionamiento que abarquen a los sectores que describe y pretende integrar.

“Concebir y aplicar programas de promoción de la innovación social para los más vulnerables, en particular facilitando una educación innovadora, formación y oportunidades de empleo para las comunidades más desasistidas, luchar contra la discriminación (por ejemplo, de los discapacitados) y desarrollar una nueva agenda para la integración de los inmigrantes con el fin de que puedan explotar plenamente su potencial" (Europa 2020, 2010, p. 25).

Las políticas de e-inclusión sobre las que se elaboraron estos documentos (i2010 i Europa 2020) se basaron en el Consejo de Lisboa del año 2000, momento en el cual la Comisión Europea accedió a tener un impacto decisivo en la erradicación de la pobreza y la exclusión social para el 2010. En aquel Consejo se animaba a los Estados miembros a establecer medidas concretas en sus planes nacionales de acción contra la pobreza y la exclusión social, y a mejorar el acceso y las oportunidades que las TICs pudieran ofrecer para alcanzar tales medidas. En la Declaración Ministerial de Riga de 2006, donde se acordó priorizar fondos europeos para políticas de e-inclusión a nivel social y territorial, la Comisión Europea identificó seis áreas en las cuales fomentar la inclusión digital. Una de ellas, Socio-Cultural e-Inclusion,

DOI: ri14.v11i1.509 | ISSN: 1697-8293 | Año 2013 Volumen 11 N 01 | ICONO14 
establecía que se debía permitir a las minorías, a los inmigrantes y marginados y a los jóvenes integrarse plenamente en las comunidades y participar en la sociedad mediante el uso de las TICs. Sin embargo, desde el Consejo de Lisboa del año 2000 al informe estratégico de la Comisión Europa 2020 de 2010, la e-Inclusion continuaba sin fondos y planes concretos de desarrollo.

Autores como Besters y Brom (2010) deconstruyen el discurso retórico de la integración de la UE señalando que la digitalización de las políticas europeas de migración no buscan la inclusión sino un mayor control del flujo de migrantes a partir de sistemas como Schengen Information System and Eurodac ${ }^{5}$.

“The EU's trust in information technology for the purpose of border control is motivated by its promises: improved efficiency and warranted effectiveness" Besters y Brom (2010, p. 470).

Estos autores denuncian que existe una asimetría entre la UE y los inmigrantes; que el gran interés de la UE es debilitar el ejercicio de los derechos de los inmigrantes a partir de complejos y difusos procesos de burocratización. También señalan que en este proceso, las TICs no son una herramienta neutral para alcanzar metas establecidas sino que forman parte de un proceso más ambicioso dentro de las fronteras físicas y virtuales. Besters y Brom observan, básicamente, tres problemas: a) el control democrático en sistemas de información b) el debilitamiento de la posición legal de los inmigrantes; y c) la investigación de la eficacia de los sistemas de información como un instrumento político.

\section{La asimetría de la e-inclusión}

Los resultados de nuestro análisis sobre uso y apropiaciones de las TICs en los colectivos e-migrantes franceses (comunitarios) y ecuatorianos (no comunitarios) no arrojan que la Sociedad de la información se haya erigido como más igualitaria, tal como pretende establecer el PNI de Cataluña y los documentos de la Comisión Europea.

Para analizar el uso y la apropiación diferenciada de las TICs entre ambos colectivos observados, este estudio discriminó la "técnica" (para describir el "saber cómo") de la "tecnología" (como el "saber hacer"). En el caso de la "tecnología" o "saber hacer", no nos referimos al saber sino al poder, no es conocimiento sino 
capacidad para actuar. Por el contrario, en la "técnica" o "saber cómo" hacer algo sí es conocimiento, pero no garantiza la capacidad de hacer, del poder para actuar. Se establece esta disociación para analizar si existen diferencias y desigualdades en los tipos de usos que realizan en las TICs los colectivos franceses y ecuatorianos (Tablas 1 y 2).

En el caso del colectivo francés casi el 100\% de la muestra tiene el conocimiento del uso de la "técnica" en las operaciones más habituales en Internet; y los ecuatorianos sólo podrían equipararse en el envío y la recepción de mensajes por correo electrónico, ya que en el resto de las operaciones la "técnica" bajaría aproximadamente a un $65 \%$ e incluso hasta un $38 \%$.

\section{Operaciones que realiza en Internet}

\begin{tabular}{|l|l|}
\hline Qué operaciones sabe realizar? (Francia) & Porcentaje de casos \\
\hline Recibir y transmitir mensajes & $100,0 \%$ \\
\hline Recibir y transmitir mensajes con attachments & $98,7 \%$ \\
\hline Encontrar información en el web con buscadores & $94,7 \%$ \\
\hline Sabe descargar ficheros a su ordenador & $98,7 \%$ \\
\hline
\end{tabular}

Tabla 1: Operaciones que realiza en Internet.

Fuente: Elaboración propia

\section{Operaciones que realiza en Internet}

\begin{tabular}{|l|l|}
\hline Qué operaciones sabe realizar? (Ecuador) & Porcentaje de casos \\
\hline Recibir y transmitir mensajes & $92,6 \%$ \\
\hline Recibir y transmitir mensajes con attachments & $63,2 \%$ \\
\hline Encontrar información en el web con buscadores & $67,6 \%$ \\
\hline Sabe descargar ficheros a su ordenador & $38,2 \%$ \\
\hline
\end{tabular}

Tabla 2: Operaciones que realiza en Internet.

Fuente: Elaboración propia

La diferencia de la "técnica" también es significativa en los indicadores que se presentan en la Tablas 3 y 4, y las desigualdades son aún más reveladoras en la relación "técnica-consumo". Por ejemplo, la compra de libros, entradas, música,

DOI: ri14.v1 1i1.509 | ISSN: 1697-8293 | Año 2013 Volumen 11 Nº 01 | ICONO14 
etc., por Internet de los franceses equivaldría a un 89,3\%; y en el caso de los ecuatorianos sería de un $11,9 \%$. Si se mira las reservas -viajes, alojamiento, alquiler coche, etc.- los franceses pueden alcanzar un 89,3\%; mientras que los ecuatorianos arribarían a un 31,1\%. La "búsqueda de trabajo" es el único indicador donde el porcentaje es más alto en el caso ecuatoriano, pero no es significativo. Se podría constatar entonces que existe una brecha entre e-migrantes-ricos e e-migrantespobres que se evidenciaría en el uso de la "técnica".

\section{Usos de Internet}

\begin{tabular}{|l|l|}
\hline $\begin{array}{l}\text { ¿Utiliza Internet para hacer alguna de las siguientes } \\
\text { cosas? (Francia) }\end{array}$ & $\begin{array}{l}\text { Porcentaje de } \\
\text { casos }\end{array}$ \\
\hline transmitir y recibir mails & $100,0 \%$ \\
\hline participar en chats & $46,7 \%$ \\
\hline comprar (libros, entradas, música, etc) & $89,3 \%$ \\
\hline reservas (viajes, alojamiento, alquiler coche) & $89,3 \%$ \\
\hline operaciones bancarias & $86,7 \%$ \\
\hline trabajar desde casa & $66,7 \%$ \\
\hline buscar trabajo & $57,3 \%$ \\
\hline buscar noticias online & $86,7 \%$ \\
\hline videojuegos (jugar) & $25,3 \%$ \\
\hline transmitir fotos familiares & $81,3 \%$ \\
\hline bajar software & $60,0 \%$ \\
\hline buscar información sobre servicios públicos & $81,3 \%$ \\
\hline consultas culturales (bibliotecas, diccionarios...) & $77,3 \%$ \\
\hline llamar online & $84,0 \%$ \\
\hline videoconferencias & $41,3 \%$ \\
\hline organizar actividades de los niños & $34,7 \%$ \\
\hline buscar recetas de cocina & $72,0 \%$ \\
\hline conectarse con amigos cuando está desanimado & $62,7 \%$ \\
\hline
\end{tabular}

Tabla 3: Operaciones que realiza en Internet.

Fuente: Elaboración propia 


\section{Usos de Internet}

\begin{tabular}{|l|l|}
\hline $\begin{array}{l}\text { ¿Utiliza Internet para hacer alguna de las siguientes } \\
\text { cosas? (Ecuador) }\end{array}$ & $\begin{array}{l}\text { Porcentaje de } \\
\text { casos }\end{array}$ \\
\hline transmitir y recibir mails & $76,1 \%$ \\
\hline participar en chats & $32,8 \%$ \\
\hline comprar (libros, entradas, música, etc) & $11,9 \%$ \\
\hline reservas (viajes, alojamiento, alquiler coche) & $31,3 \%$ \\
\hline operaciones bancarias & $23,9 \%$ \\
\hline trabajar desde casa & $13,4 \%$ \\
\hline buscar trabajo & $59,7 \%$ \\
\hline buscar noticias online & $40,3 \%$ \\
\hline videojuegos (jugar) & $16,4 \%$ \\
\hline transmitir fotos familiares & $40,3 \%$ \\
\hline bajar software & $26,9 \%$ \\
\hline buscar información sobre servicios públicos & $29,9 \%$ \\
\hline consultas culturales (bibliotecas, diccionarios...) & $16,4 \%$ \\
\hline Ulamar online & $11,9 \%$ \\
\hline videoconferencias & $28,4 \%$ \\
\hline organizar actividades de los niños & $6,0 \%$ \\
\hline buscar recetas de cocina & $19,4 \%$ \\
\hline conectarse con amigos cuando está desanimado & $26,9 \%$ \\
\hline
\end{tabular}

Tabla 4: Operaciones que realiza en Internet.

Fuente: Elaboración propia

Las diferencias "tecnológicas", poder y capacidad para actuar en el contexto local y global, se pueden encontrar en los indicadores "operaciones bancarias" -86,7\%- 0 "trabajar desde casa" -66,7\%-. En el caso ecuatoriano, esos mismos indicadores reflejan un $23 \%$ y un $13 \%$. Los resultados señalan también, que una de las razones por las cuales los franceses se comunicarían con más frecuencia con su país de origen sería por negocios -16,0\%- mientras que en el caso ecuatoriano sólo lo haría el 2,7\%. Por lo tanto, existirían importantes diferencias y desigualdades en el uso de la "técnica" y la "tecnología" entre los e-migrantes franceses y ecuatorianos en el contexto local y global. 
Para la ex secretaria de Inmigración, Adela Ros, existe una desigualdad en el acceso a los espacios de conectividad marcada por la diferencia de clases. Para ella, los ricos viven de espalda a los espacios comunes que estable el PNI, porque no estarían conviviendo ni compartiendo lugares comunes con la población de destino, sino extendiendo, gracias a las TICs, sus espacios identitarios con el país de destino.

La diferencia de clases y la desigualdad, a la cual hacen referencia Ros y también el secretario Amorós, en términos de "conexión", serían las formas actuales de explotación en un mundo que distingue entre aquellos que tienen domicilio fijo, documentos de identidad y de crédito, acceso a la información y el dinero y entre aquellos que carecen de tales conexiones (Boltanski y Chapello, 2002). Según estos autores, al recorrer los discursos y los trabajos estadísticos dedicados a los excluidos, se encontraron que las desventajas sociales son miradas como consecuencia de relaciones entre miseria y culpa, o de características personales fácilmente transformables en factores de responsabilidad individual. Tal enfoque permitía eliminar la visión estructural de la explotación que iba ligada a la noción de clase: “la exclusión se presenta más como un destino (contra el que hay que luchar) que como el resultado de una asimetría social de las que algunas personas sacarían partido en prejuicio de otras" (Boltanski y Chapello, 2002, p. 458).

La consolidación de los mercados transnacionales fijó una retórica de inclusiónexclusión (García Canclini, 2004). Las sociedades contemporáneas, que inicialmente fueron concebidos en términos de capas o niveles, o distinguidas por las identidades étnicas o nacionales, ahora son pensadas políticamente bajo la metáfora de la sociedad red. Esta sociedad se define como una estructura social global basada en redes activadas por el uso de la información digital y de las tecnologías de la comunicación (Castells, 2009; Castells et al, 2003). La exclusión de las redes de la información y la comunicación se está convirtiendo en una nueva forma de exclusión social en nuestras sociedades contemporáneas (Castells, 2004). El mundo conexionista parece haber diluido la condición de explotado, que antes se definía en el ámbito laboral. La explotación era, en primer lugar, una explotación por el trabajo.

ICONO14 | Año 2013 Volumen 11 № 01 | ISSN: 1697-8293 | DOI: ri14.v11i1.509 


\section{La asimetría del espacio geográfico e}

\section{intercultural}

Un segundo elemento de desigualdad y diferencia entre los colectivos e-migrantes comunitarios y no comunitarios en relación con la "tecnología" o "saber hacer", es la capacidad de desplazamiento en los espacios geográficos e interculturales. Los no comunitarios no tienen tal capacidad de libre circulación, un bien que se administra y distribuye de forma desigual y, por ello, el "saber hacer" actúa como un pujante estratificador social. Los comunitarios funcionarían como las redes eléctricas (no necesita aglomeraciones importantes y permite que cualquier lugar se convierta en centro) y los no comunitarios como las redes ferroviarias (requieren de grandes aglomeraciones urbanas y un centro). Existirían entonces vinculaciones estructurales y complementarias entre unos y otros. Los no comunitarios son indispensables para el nomadismo y el enriquecimiento de los comunitarios. La explotación se fortalecería dentro de ese mundo conexionista a partir de la inmovilidad de los no comunitarios y gracias a la duración con que los nómadas acumulan movilidad y multilocalización. El "saber hacer" radica en la capacidad de lograr no ser desconectado, de añadir conexiones, en la movilidad geográfica e intercultural y en la capacidad de mantener las redes multiconectadas. Ahora, el capital social y económico se extiende a las relaciones internacionales y desplaza su eje de las posesiones territoriales a los recursos intangibles de la movilidad y las conexiones.

Estos elementos de capacidad, de "saber hacer" -conexión/desconexión, movilidad/ inmovilidad- darían cuerpo a una nueva hipótesis: las TICs pueden contribuir a la formación de nuevos tipos de guetos e-migrantes en los países donde viven. Los franceses comunitarios que dominan la técnica y la tecnología, y habitan en Cataluña, no pertenecen al lugar que habitan, por lo tanto, sus compromisos o voluntades de "integración" con el lugar son otros diferentes al de los ecuatorianos, no comunitarios, que sólo dominan la técnica y carecen de la conexión (pasaporte, crédito, acceso a la información y el dinero) y la movilidad (geográfica e intercultural).

Esto lo comprobamos en el dato que arroja que el $46 \%$ del colectivo francés trabaja en empresas multinacionales y sólo un $2 \%$ lo hace en el caso de los ecuato-

DOI: ri14.v1 1i1.509 | ISSN: 1697-8293 | Año 2013 Volumen 11 Nº1 | ICONO14 
rianos. Los ecuatorianos están totalmente insertos en el mercado laboral catalán, no tienen las redes multiconectadas de los franceses, en consecuencia, sus vidas tienen otro compromiso y ligamen con la ciudad que habitan, son "prisioneros del lugar", así lo regulan las leyes de extranjería. Por ende, sus proyectos, sus sueños, sus narrativas identitarias, sus compromisos están centrados en los "asuntos locales".

En cambio los franceses (comunitarios), tal como se desprende del grupo de discusión, viven "cómodos" en Cataluña y viven en su "burbuja" desde la cual conservan sus referentes culturales identitarios.

“Quiero notar que las TICs reforzaron la distancia y no la proximidad en la capacidad de integrarse en la sociedad local, en cualquier país del mundo. Te dan las herramientas para poder vivir en nuestra burbuja cultural en un país físicamente otro" (Sylvain, 41 años, 10 años en Barcelona).

Para ellos, Cataluña es un lugar agradable, que les permite desarrollar sus negocios y sus espacios culturales propios, así como darles una educación a sus hijos en francés y con la facilidad de la proximidad de su país de origen. La posibilidad del desplazamiento por la UE, en el caso francés, les permite vivir "despreocupados" de los asuntos de "su ciudad" en Cataluña, que es sólo una localidad entre muchas, y todas ellas insignificantes desde el punto de vista estratégico del ciberespacio, que, aunque virtual, es ahora su verdadero hogar.

En otras palabras, las TICs no han superado antiguas formas de explotación social, sino que refuerzan los modelos sociales ya existentes. Si bien ambos colectivos tendrían acceso a la conectividad, en el caso francés parecería que se refuerza -a partir de las redes sociales- su cosmopolitismo dentro de los mercados económicos globales. Es decir, el discurso de la Sociedad de la información pregona la mayor igualdad, pero es en el uso de las TICs donde se observa que las realidades desigualdades y diferencias sociales no habrían cambiado.

\section{E-migrantes: una nueva configuración del}

\section{espacio TGS}

Es indudable que las TICs estarían cambiando la idea de fronteras para las cien-

ICONO14 | Año 2013 Volumen 11 № 01 | ISSN: 1697-8293 | DOI: ri14.v11i1.509 
cias sociales en general (sociología, geografía, comunicación, etc.) y para las retóricas discursivas de las políticas de integración migratorias en particular. Nuevos espacios y configuraciones tecnológicas, geográficas y sociales (TGS) que desafiarían paradigmas como el nacionalismo metodológico, el territorio. Como señalan Wimmer y Glick Schiller (2002, p. 302) el llamado nacionalismo metodológico es “la forma política y social natural de la nación/estado/sociedad del mundo moderno". De acuerdo con esta suposición (nacional), las sociedades tiene límites que, naturalmente, coinciden con los límites territoriales definidos y controlados por los Estados-nación, epistemológicamente hablando. Esta correlación no es sorprendente, ya que el surgimiento de la sociología moderna coincidió con la fundación de los Estados-nación, las sociedades nacionales y el sistema político internacional. Estos autores sostienen también que este tipo de enfoque nacional restringió el estudio del fenómeno migratorio y lo limitó al confinamiento del paradigma: estado-nación/inmigración.

Sin embargo, el discurso de la Sociedad de la información promete, con la intervención de las TICs, no solo nuevos territorios transnacionales, sino también un camino para la inclusión y la igualdad de los inmigrantes. La creciente movilidad que atraviesa a los estilos de vida actual, de "estar juntos en la distancia", pondría contra las cuerdas los límites de la territorialidad como categoría para pensar en múltiples identidades culturales, las prácticas sociales transnacionales y la pertenencia cosmopolita (Beck, 2003, 2006; Beck y Grande, 2010; Beck \& Sznaider, 2006; Benhabib, 2004; Chang, 2010; Georgiou, 2010; Maharaj, 2010).

Las ciudades se configuran ahora como nuevos espacios TGS, espacios donde las personas de múltiples orígenes geográficos y culturales coexisten y generan nuevos escenarios en los cuales intentan intervenir las administraciones gubernamentales para delinear las identidades individuales y/o colectivas. En este escenario se configura nuevos multi y transdisciplinarios espacios TGS, espacios desconocidos, que tienen nuevas lógicas y formas de producción, de comunicación y de la circulación de la información en un contexto de cambio tecnológico rápido y continuo. Las TICs han intervenido notablemente la mediación y la circulación de la comunicación y la información después de la digitalización de la información. Las TICs permiten crear ahora nuevas prácticas y lógicas sociales configuradas por nuevas relaciones múltiples entre el espacio-tiempo-lugar. Por ejemplo, hoy la telefonía móvil permite la conectividad en todo el mundo a través de comunicaciones por 
satélite. Estas innovaciones tecnológicas establecen nuevos espacios transnacionales que nos obligan a revisar conceptos tradicionales como migrante, inmigrante, integración, asimilación, etc., en las sociedades de destino y dentro del campo de la investigación de la migración internacional.

En este nuevo espacio TGS, Internet tiene un papel importante. El e-migrante, pensado como un nómada conectado a un dispositivo como el teléfono móvil o las TICs, construiría (aparentemente) relaciones transnacionales. Siguiendo esta línea de pensamiento, de Kerckhove (2005) argumenta que la globalización, la transnacionalización, llega a todos, incluso aquellos que no tienean un teléfono móvil o Internet. Otros autores acuerdan sobre la existencia de nuevas extraterritorialidades o espacios, ya sean físicos o virtuales. Es en estos espacios que las TICs podrían dar lugar a un proceso de tecnosociabilidad que afectaría a los migrantes de manera privilegiada en el desarrollo de nuevos modos de interacción cultural y social y en las nuevas formas de la comunicación transnacional, global y virtual (Bernal, 2004; Escobar, 2000; Gómez Cruz, 2003; Graham y Marvin, 2001; Rheingold, 1996). Esto sugiere que la aparición de nuevas formas de socialización e identificación en el paisaje mediático mundial, todavía incipiente, comienza con el proceso de desterritorialización.

El término e-migrante propuesto en este artículo, nos permite articular dialécticamente la relación entre el e-migrante y esas múltiples dimensiones espaciales tecnológicas, geográficas y sociales que se configuran en la Sociedad de la información. La notación e-migrante se ve reforzada por la imposibilidad de analizar las experiencias de los inmigrantes y emigrantes de forma independiente. Morfológicamente, el prefijo "in-", de inmigrante, aporta una carga semántica de incorporación/inclusión en el país de destino. A su vez, el prefijo "e-", de emigrante, añade el significado de la salida del país de origen. Los procesos migratorios actuales, gracias a las TIC, no escapan ni descuidan la inclusión de las dimensiones tecnológicas, del espacio geográfico y social entre los países de destino y origen. En este contexto, tiene sentido hablar de e-migrantes. Por otra parte, si se analiza la migración como un proceso de continuo movimiento, si se abre un proceso de interacciones, conectividades, virtualidades, convergencias y ubiquidades, la idea de "salir" o "entrar" de un espacio social virtual parece, en estos términos, discutible. 


\section{Discusión}

Los resultados de este estudio ilustran cómo: a) el concepto e-migrante -conformado por el nuevo espacio TGS- puede proporcionar un buen marco analítico en el actual contexto de dos procesos interrelacionados que son la migración transnacionales y la Sociedad de la información; y b) cómo las políticas de integración gestionadas en clave cultural en Cataluña, a partir de la irrupción de las TICs y dentro de la llamada Sociedad de la información, quedaron atrapadas en la paradoja de administrar políticas migratorias cada vez más locales en un mundo cada vez más estructurado por los procesos transnacionales.

En el contexto de la Sociedad de la información, el e-migrante marcaría un proceso general de trasformación comunicacional histórico, como un nómada-inmigrante-conectado, en movimiento, que basa sus alianzas dentro y fuera de su propio grupo de pertenencia, sin cortar sus vínculos sociales, gracias a las nuevas lógicas comunicacionales y culturales que generaron las TICs. Sin embargo, esas nuevas lógicas mediadas por las TICs no serian suficientes para "integrar" al emigrante. No se desprende de los resultados de nuestro estudio que la "integración a una cultura común" del PNI catalán o la e-inclusión que pretende establecer la Comisión Europea hayan comportado igualdad de oportunidades, o superado las fracturas sociales para los e-migrantes ecuatorianos no comunitarios en Cataluña. Además, la participación en la cultura común catalana que pretende el PNI sería un fracaso en el caso de los e-migrantes franceses, que señalan que las TICs "reforzaron la distancia y no la proximidad para integrarse en la sociedad local". Incluso sería importante plantear, a la luz de los resultados presentados en "La asimetría de la e-inclusión", que ser un e-migrante no necesariamente implica tener el acceso a las redes transnacionales o construir relaciones transnacionales. No es lo mismo tener al alcance la "técnica" que la "tecnología". En otras palabras, para ser un e-migrante transnacional dentro de la Sociedad de la Información se necesita verdaderas posibilidades de integración social, política y económica; representaciones sociales y políticas; redes sociales y de trabajo; etc., además del acceso virtual a la vinculación con diversos aspectos estructurales, sociales, legales y culturales.

El uso y la apropiación de las TICs de franceses y ecuatorianos, diferenciado entre "técnica" y "tecnología", señalaría la imposibilidad de representar a la Sociedad de la información como el espacio o territorio virtual que permita un cos-

DOI: ri14.v1 1i1.509 | ISSN: 1697-8293 | Año 2013 Volumen 11 Nº1 | ICONO14 
mopolitismo de libre adscripción identitaria. Por el contrario, es justamente en el uso de las TICs donde se observa que las realidades sociales no habrían cambiado. Las sociedades transformaron sus apariencias a partir de las TICs, pero en el fondo sus realidades y conflictos sociales de intereses opuestos e inevitables continúan persistiendo. En palabras del secretario de Inmigración Oriol Amorós: "el problema no es la diversidad cultural, sino las diferencias entre ricos y pobres, las diferencias de clases dentro de un sistema capitalista". Es decir, el mismo problema que existía en la sociedad industrial y postindustrial.

Este estudio comparativo no podría confirmar que la diversidad cultural sea gestionada para integrar a la inmigración, tal como establecen las políticas migratorias de la UE y de Cataluña, sino para categorizarlas y clasificarlas, tal como se comprueba en el apartado "La cultura identitaria como retórica política de la exclusión en España y Cataluña". Nuestros resultados apuntan que el colectivo ecuatoriano no comunitario no parecería tener al alcance la posibilidad de sumarse al acceso multicultural planetario que acompaña el discurso retórico de la Sociedad de la información que promete un espacio social más igualitario, participativo y cohesionado.

Las políticas migratorias procuran definir un marco teórico del modelo de "integración", en el contexto de la Sociedad de la información, precisando criterios de solidaridad, transparencia, libertad e igualdad, tal como se señaló en la sección "La retórica del lenguaje de la Sociedad de la información". Pero como observamos en los apartados "La asimetría de la e-inclusión” y “La asimetría del espacio geográfico e intercultural", el modelo de "integración" propuesto no resiste los criterios de igualdad democrática. La diferencia cultural no explicaría la causa del "problema de integración", porque la gestión de la diversidad cultural ocultaría discriminaciones jurídicas, políticas y desigualdades en el acceso a las estructuras de poder y de riqueza; así como también de movilidad geográfica.

Los e-migrantes, gracias a las TICs, están insertos en los nuevos espacios TGS y en sus flujos comunicacionales, pero la jurisprudencia no les permite la integración al territorio, a la ciudadanía, a la economía, a la sociedad, etc. Se integran las relaciones virtuales, no las físicas. Las TICs abren la perspectiva de nuevas formas de existencia, individuales y colectivas, pero también permiten la emergencia de nuevas estrategias y dispositivos de control: Schengen Information System (SIS), Sistema de identificación europeo de visados (VIS), etc. Las redes son estructuras 
abiertas y siempre en expansión, pero también son estructuras que reorganizan las relaciones de poder. Así, las TICs y el PNI (o las directrices políticas migratorias de la UE) refuerzan nuestra hipótesis: ciertas poblaciones de inmigrantes son gestionadas y controladas por los estados europeos en función de sus vínculos económicos, geoestratégicos, religiosos e histórico. Las TICs ayudarían a incluir los flujos financieros y económicos en la Sociedad de la información, pero no los flujos migratorios.

Finalmente, este trabajo apunta al concepto de e-migrantes para repensar los imaginarios sociales y las mediaciones y articulaciones que se producen en la retórica de la comunicación, la cultura y la política migratoria transnacional en el marco de la Sociedad de la información. E-migrantes es un concepto que, con todas sus posibles derivaciones, abre el debate en los nuevos procesos, mecanismos y roles del Estado frente a la actual necesidad de satisfacer las necesidades de inclusión social, jurídica, económica, política y tecnológica.

El término e-migración abre también la posibilidad de repensar nuevas realidades, múltiples y no únicas. Así, la e-migración, entendida como un proceso múltiple y constante de transformación dentro de la rápida y cambiante Sociedad de la información, permitiría renunciar a las identidades fijas en favor de un fluir de devenires múltiples. Para ello, es fundamental el acompañamiento de las políticas migratorias instaurando nuevas categorías retóricas, nuevos tropos, alusiones figuradas en favor de la diferencia positiva y no como algo negativo, como una amenaza.

El cuerpo de los e-migrantes, cada vez más, es un interjuego complejo de fuerzas sociales y simbólicas que se construye y reconstruye en el flujo constante de conexiones virtuales identitarias y culturales dentro de la Sociedad de la información. Todos estos cambios comportan vivir en realidades sociales cada vez más complejas. La retórica de la integración de las políticas migratorias debiera tener en cuenta esos cambios, para que tal nivel de complejidad social se vea reflejado luego en la elaboración de las legislaciones migratorias. 


\section{Notas}

[1] Este artículo se basa en ideas de la tesis de doctorado: E-migración. las TICs como herramienta de gestión de las políticas de inmigración en Cataluña (Olivera, 2011). El punto de partida la tesis doctoral fue: ¿qué está ocurriendo con los procesos identitarios en el marco de las políticas públicas del Estado-nación que pretende "integrar" al migrante cuando éste tiene la posibilidad, a diferencia de migraciones pasadas, de seguir en contacto "directo" con su acervo cultural a partir de las TICs?

[2] La migración se redefine con el ingreso del Estado español en la Comunidad Económica Europea (CEE) en 1986. El control de las fronteras españolas se convierte en una cuestión de interés europeo. En 1984 se promulgó la Ley de Asilo y en 1985 se sancionó la Ley de Derechos y Libertades de los Extranjeros, conocida como Ley de Extranjería. Estas normas originaron el Derecho español de extranjería y, junto con algunas sentencias del Tribunal Constitucional, sentaron las bases en el control legal y policial del flujo migratorio. A partir de ese momento, se permite la libre circulación de personas europeos dentro de los países que conforman la Unión Europea (UE), derivándose de ello que de forma implícita se empiece a distinguir entre "ciudadanos europeos o comunitarios" (aquellos cuyo origen es un país de la UE) e "inmigrantes, no comunitarios o extra comunitarios" (aquellos cuyos orígenes no son países comunitarios).

[3] Para más información consultar "La immigració en cifres": http://www.gencat.cat/dasc/publica/butlletiIMMI/xifres4/index.htm

[4] Citado por Pedone, Claudia y Gil Araujo, Sandra en: “Los laberintos de la ciudadanía. Políticas migratorias e inserción de las familias migrantes latinoamericanas en España" En:http://devel. ciimu.org/uploads/20090522/REHMU_Gil_Araujo_Pedone_laberintos_ciudadania.pdf

[5] En el marco del sistema Eurodac (Europea Dactiloscópica -Sistema Automatizado de Identificación de Huellas Dactilares (AFIS) de la Unión Europea-), se formó la segunda generación del Sistema de Información de Schengen y el Sistema de identificación europeo de visados. Más información en: http://ec.europa.eu/justice_home/index.html

\section{Referencias}

Almiron, N. (2002). Els amos de la globalització. Barcelona: Plaza \& Janes. Bartra, R. (1996). Las redes imaginarias del poder politico. México: Océano. Becerra, M. (2003). Sociedad de la información: proyecto, convergencia, divergencia. Col. Enciclopedia Latinoamericana de Sociocultura y Comunicación. Buenos Aires: Norma. 
Beck, U. (2003). Toward a new critical theory with a cosmopolitan intent. Constellations, (10), 453-468.

Beck, U. (2004). Cosmopolitical realism: on the distinction between cosmoplitanism in philosophy and the social sciences. Global Networks, (4), 109-30.

Beck, U. (2006). The cosmopolitan vision. Cambridge. UK: Polity.

Beck, U. \& Sznaider, N. (2006). Unpacking cosmopolitanism for the social sciences: A research agenda. British Journal of Sociology, (57), 1-23.

Beck, U., \& Grande, E. (2010). Varieties of second modernity: The "cosmopolitan turn" in social and political theory and research. British Journal of Sociology, (61), 409-443.

Benhabib Seyla (2004). The Rights of Others: Aliens, Residents and Citizens. Cambridge: University Press.

Bernal, P. (2004). La interfaz: un dispositivo de comunicación para posibilitar la interacción entre las comunidades. En Actas del VII Congreso Latinoamericano de ciencias de la comunicación (La Plata, Argentina - 0ctober 11-16, 2004)

Besters \& Brom (2010). Greedy' Information Technology: The Digitalization of the European Migration Policy. European Journal of Migration and Law, (12), 455470.

Boltanski, L. \& Chapello, É. (2002). El nuevo espíritu del capitalismo. Madrid: Akal.

Castells, M., I. Tubella, T. Sancho, I. Diaz de Isla \& B. Wellman (2003). La Societat Xarxa a Catalunya. Barcelona: La Rosa del Vents Mondadori.

Castells, M. (2004). La era de la información: economía, sociedad y cultura, Vol. III. México, Argentina, España: Siglo XXI Editores.

Castells, M (2009). Comunicación y Poder. Madrid: Alianza Editorial.

Chang, K.-S. (2010). The second modern condition? Compressed modernity as internalized reflexive cosmopolitization. British Journal of Sociology, (61), 444464.

Chillón, A. (1998). El giro lingüístico y su incidencia en el estudio de la comunicación periodística. Análisi. Quaderns de comunicació i cultura, (22), 63-98.

Ford, A. (1999). La marca de la bestia: identificación, desigualdades e infoentretenimiento en la sociedad contemporánea. Buenos Aires: Norma. 
García Canclini, N. (2004). Diferentes, desiguales y desconectados. Mapas de la interculturalidad. Barcelona: Gedisa.

Generalitat de Catalunya (2008). Pacte Nacional per a la Immigració. Barcelona: Secretaria per a la Immigració.

Georgiou, M. (2010). Identity, Space and the Media: Thinking through Diaspora. Revue Européenne des Migrations Internationales, 26, (1), 17-35.

Graham, S. \& Marvin, S. (2001). Splintering Urbanism. Londres: Routledge.

Gómez Cruz, E. (2003). Cibersexo ¿la última frontera del eros? Un estudio etnográfico. México: Universidad de Colima.

Ibáñez, T. (2002). La incógnita del extraño. Una aproximación a la significación sociológica de la "inmigración comunitaria". Barcelona: Anthropos (IX-XII)

Institut de Recerca de la UOC (IN3) (2007). Projecte Internet Catalunya (PIC). En http://www.uoc.edu/in3/pic/cat/egovernanca/informe.html

Izquierdo, A. (2002, 5 de agosto). El éxito de lo impreciso. El País.

Escobar, A. (2000). Welcome to Cyberia: notes on the anthropolgy of cyber cultura. En The Cybercultures reader. Edites by David Bell and Barbara M. Kennedy, London and New Cork: Routledge.

Comisión Europea (2010). Europa 2020.Una Estrategia para un crecimiento inteligente, sostenible e integrador. Recuperado de http://ec.europa.eu/commission_2010-2014/president/news/documents/pdf/20100303_1_es.pdf

Jiménez Becerra, J. (2010). El papel de las TIC en el desarrollo: una mirada desde la construcción social de la tecnología en el caso Ecuatoriano. Iconos. Revista de Ciencias Sociales, Quito, (37), 87-97.

Kerckhove, D.(2005). Los sesgos de la electricidad. En Lección inaugural del curso académico 2005-2006 of the UOC, Retrieved March 12, 2011, from http://www. uoc.edu/inaugural05/esp/kerckhove.pdf

Maharaj, S. (2010). Small change of the universal: Beyond modernity? British Journal of Sociology, (61), 565-578.

Mattelart, A. (2007). Historia de la Sociedad de la información. Barcelona: Paidós.

Olivera, N. (2011). E-migración. Las TICs como herramienta de gestión de las políticas de inmigración en Cataluña. Barcelona: Universitat Autònoma de Barcelona.

Rheingold, Howard (1996). La Comunidad Virtual. Barcelona: Gedisa. 
Shore, C. \& Wright, S. (1997). "Policy. A new field of Anthropology", Shore, Cris y Wright, Susan (eds.) Anthropology of Policy. Critical perspectivas on Governance and Power. Londres: Routledge (3-9)

Stolcke, V. (1994). Europa: nuevas fronteras, nuevas retóricas de exclusión", En VVAA Extranjeros en el paraíso. Barcelona: Virus (235-266).

Tremblay, G. (2003). La Sociedad de la información y la nueva economía. Promesas, realidades y faltas de un modelo ideológico. Telos, (54), 16-23.

Valverde, J.M. (1993). Nietzsche, de filólogo a Anticristo. Planeta: Barcelona.

Vercelli, A. (2010). Reconsiderando las tecnologías sociales como bienes comunes. Íconos. Revista de Ciencias Sociales, Quito, (37), (55-64).

Webster, F. (2006). La Sociedad de la información revisitada. Biblioteca Universitaria, January-June, (9), Universidad Nacional Autónoma de México, pp. 22-44.

Wimmer, A. \& N. Glick Schiller (2002). Methodological nationalism and beyond: nationstate building, migration and the social sciences. Global Networks, (2), 30134. 